\title{
最密堆积中空隙分布的学习技巧
}

孙宏伟 ${ }^{*}$, 陈兰

南开大学化学学院, 天津 300071

摘要: 六方最密堆积和立方最密堆积是金属晶体中最常见的结构, 其正四面体空隙和正八面体空隙的分布是学生学 习的难点。本文将揭示密置双层-最密堆积-离子晶体结构中空隙的分布规律, 进而将典型离子晶体结构与最密堆积 中的空隙分布相关联。这对学生掌握空隙分布的规律性, 理解金属和离子晶体结构, 提升晶体结构的学习效果大有 帮助。

关键词: 空隙; 金属晶体; 离子晶体; 密置层; 最密堆积

中图分类号: G64; O6

\section{Techniques of Learning the Arrangement of the Holes in Close-Packed Structures}

\author{
Hongwei Sun ${ }^{*}$, Lan Chen \\ College of Chemistry, Nankai University, Tianjin 300071, China.
}

\begin{abstract}
The $h c p$ and $c c p$ are the two main structures that most metals adopt. The tetrahedral holes and octahedral holes in these structures are commonly difficult for students to grasp. In this paper, we focus on the arrangement of the holes in the close-packed structures. This is also very helpful in learning ionic crystals.
\end{abstract}

Key Words: Hole; Metallic crystal; lonic crystal; Close-packed layer; Close-packed structure

在结构化学课程的空间结构部分, 两种最密堆积形式一一六方最密堆积 $(h c p)$ 和立方最密堆积 $(c c p)$ 是金属晶体的重要知识点, 同时也是学习简单二元离子晶体结构的基础。在课程教学中我们 发现, $h c p$ 和 $c c p$ 中的空隙的种类、分布及数目 ${ }^{[1]}$ 等是学生学习的难点, 多数学生仅通过简单记忆来完 成学习, 并不能掌握正四面体和正八面体两类空隙的分布规律以及其与典型二元离子晶体结构的关 系。

本文将介绍密置双层、最密堆积以及典型二元离子晶体结构中空隙分布的规律及其内在的关联。 掌握这个关键点, 就可以很好地理解最密堆积中空隙分布的规律性、进而理解典型二元离子晶体结 构的规律性，对提升晶体结构的学习效果大有帮助。

\section{1 密置双层与最密堆积中空隙的分布}

\section{1 密置层中的三角形空隙}

等径圆球按一维方向紧密排列成为密置列, 将相互平行并共平面的密置列紧密靠拢形成密置层, 
密置层是等径圆球在平面上最密排列的唯一形式 ${ }^{[2]}$ 。在密置层中每个球和周围 6 个球接触, 并形成 6 个三角形空隙, 每个空隙由 3 个球围成。在最密堆积中, 各层球的堆积位置和正四面体、正八面体 空隙中心的位置均与三角形空隙相关, 因此首先必须明确密置层中球和三角形空隙的位置。

如图1所示, 在密置层中, 将球心在密置层平面的投影位置定义为 $\mathrm{A}$, 球周围的三角形空隙分成 两类, 数量各占一半, 其三角形顶点的朝向相反, 三角形空隙中心在密置层平面的投影位置分别定 义为 $\mathrm{B}$ 和 $\mathrm{C}$ 。

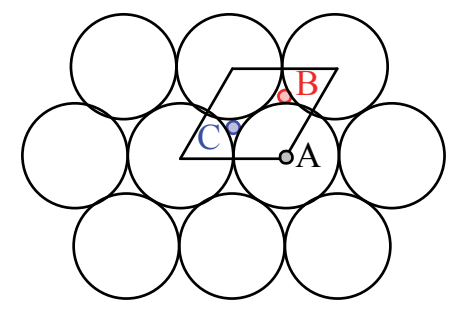

图1 密置层中球与三角形空隙的投影位置

\section{2 密置双层中球和空隙的分布}

当两个密置层进行堆积, 形成密置双层时, 上层球只能占据相互间隔的三角形空隙, 球心在密 置层平面的投影位置只能为 $\mathrm{B}$ 或 $\mathrm{C}$ 中的一种, 我们选取上层占据 $\mathrm{B}$ 位置, 如图2。

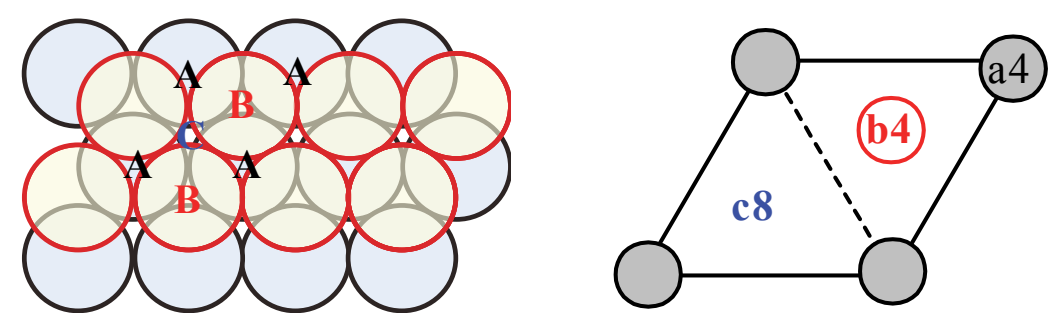

图2 密置双层及正四面体和正八面体空隙分布

在密置双层中, 原来每层的三角形空隙与另外一层的原子形成了两类空隙：一类是正四面体空 隙, 由上层的一个圆球与下层与之接触的三个圆球形成, 其中心在密置层平面投影的位置为 $\mathrm{B}$, 上层 三个圆球和下层一个圆球, 其中心投影的位置在 $\mathrm{A}$, 四面体空隙中心的投影位置一定与球心的投影 位置重合; 另一类为正八面体空隙, 由上下两层每层各三个球形成, 其空隙中心的投影位置在 $\mathrm{C}$, 一 定在所涉及的两层中球未占据的位置。

\section{3 最密堆积中球和空隙的分布}

将密置层按 $\cdots \mathrm{ABAB} \cdots$ 堆积, 则得到六方最密堆积 $(h c p)$, 其晶胞以 $\mathrm{A}$ 为原点, 为方便确定空隙位 置, 可以简单地将其看成是 $\mathrm{AB}$ 和 $\mathrm{BA}$ 两个密置双层构成的, 从1.2节的讨论可知, 正八面体空隙中心 的投影位置一定都在 $\mathrm{C}$ 位。在垂直于密置层平面方向(晶胞 $c$ 方向), 空隙中心的位置位于两个密置层 中间, 因此很简单地就可以在 $h c p$ 晶胞中标记出正八面体空隙中心的位置(图 $3 a$ ), 其分数坐标为 $1 / 3$, $2 / 3,1 / 4$ 和 $1 / 3,2 / 3,3 / 4$; 正四面体空隙中心的投影位置分别在 $A$ 和 $\mathrm{B}$ 位, 由于正四面体的顶点分别处 于 $\mathrm{A}$ 或 $\mathrm{B}$ 层, 在垂直于密置层平面方向, 空隙中心距两密置层平面的距离比为 $1: 3$ (距顶点为 3 ), 这样 就可以在 $h c p$ 晶胞中标记出正四面体空隙中心的位置, 其分数坐标为 $0,0,3 / 8 ; 0,0,5 / 8$ (正四面体 的顶点在 $\mathrm{A}$ 层)和 $2 / 3,1 / 3,1 / 8 ; 2 / 3,1 / 3,7 / 8$ (正四面体的顶点在 $\mathrm{B}$ 层)。

将密置层按 $\cdots$ ABACABAC $\cdots$ 堆积, 得到的为 $\mathrm{A} 3^{*}$ 堆积, 对比 $h c p$ 中正八面体空隙的分布, 很容易 得到其正八面体和正四面体空隙的位置(图 $3 b$ )。同理 $c c p$ 如按密置层方向划成 $h R$ 晶胞(也可以将其考 虑为在垂直于密置层方向发生畸变的A10堆积), 其八面体和四面体空隙的位置见图3c。 


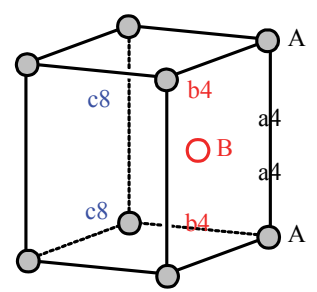

(a) $h c p$

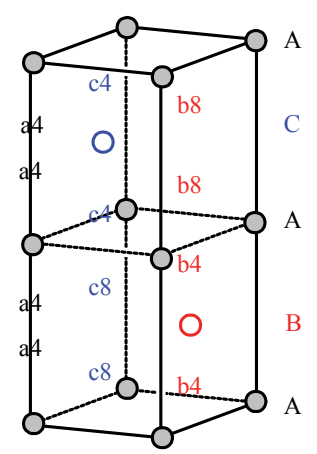

(b) $\mathrm{A} 3^{*}$

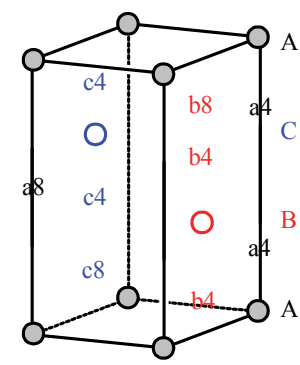

(c) A10

图3 hcp $(\mathrm{A3}) 、 \mathrm{A3}^{*}$ 和 $\mathrm{A} 10$ 中正四面体和正八面体空隙分布

\section{4 与密置层相关离子晶体的堆积周期}

在离子晶体结构的学习中, 离子晶体的堆积周期是学生不易理解的知识点。在熟知密置双层结 构、了解最密堆积中球和空隙的分布基础上, 这个难点就可以迎刃而解。

从上面的讨论可知, 对 $h c p$, 其堆积方式为 $\cdots \mathrm{ABAB} \cdots$, 在密置层 $\mathrm{A}$ 和 $\mathrm{B}$ 层中正八面体空隙的位置 为 $\mathrm{c}$, 因此球与正八面体的堆积周期为 $|\mathrm{AcBc}|$ 。NiAs型离子晶体, 阴离子堆积为 $h c p$, 阳离子占据全部 的正八面体空隙, 因此其(001)方向正、负离子密堆积层堆积表示为 $|\mathrm{AcBc}| ; \mathrm{CdI}_{2}$ 中, $\mathrm{Cd}^{2+}$ 占据一半的 八面体空隙(同层), 所以其堆积结构可写为 $|\mathrm{AcB} \square \mathrm{AcB} \square|$ 。

$h c p$ 中正四面体空隙的投影位置与球相同，投影在 $\mathrm{A}$ 位置的正四面体空隙的中心距 $\mathrm{B}$ 层近(A为正 四面体的顶点), 因此球与正四面体的堆积周期为 $|\mathrm{AbaBab}|$ 。对六方 $\mathrm{ZnS}$, 阳离子占据一半正四面体空 隙, 因此其堆积周期为 $|\mathrm{AaBb}|$ 。

再来看一下 $c c p$, 其堆积方式为 $\cdots \mathrm{ABCABC} \cdots$, 球与正八面体空隙的堆积周期为 $|\mathrm{AcBaCb}|, \mathrm{NaCl}$ 型离子晶体, 阴离子堆积为 $c c p$, 阳离子占据全部的正八面体空隙, 因此其(111)方向(与密置层垂直 方向)正、负离子密堆积层堆积表示为 $|\mathrm{AcBaCb}|$; 第21届全国高中学生化学竞赛(省级赛区)试题中 ${ }^{[3]}$, 曾涉及 $\mathrm{MgCl}_{2}$ 晶体的结构, 题目中给出 “氯离子采取立方最密堆积 $(c c p)$, 镁离子填满同层的八面体空 隙”, 考虑到 $\mathrm{Mg}$ 离子为 +2 价, 与 $\mathrm{NaCl}$ 离子晶体相比, $\mathrm{Mg}^{2+}$ 数目要少一半, 因此需要在每两层八面体 空隙中空一层, 因此其堆积周期为 $|\mathrm{AcB} \square \mathrm{CbA} \square \mathrm{BaC} \square|$ 。

对 $c c p$, 球与正四面体的堆积周期为 $|\mathrm{AbaBcbCac}|$, 立方 $\mathrm{ZnS}$ 中阳离子只占一半的正四面体空隙, 因此其堆积周期为 $|\mathrm{AaBbCc}|$ 。

\section{2 金属最密堆积中空隙分布与典型二元离子晶体结构的关系}

对于典型二元离子晶体, 可以采用以下模型, 即将负离子看成堆积, 正离子填在堆积的空隙中。 典型二元离子晶体与 $h c p$ 和 $c c p$ 两种堆积的空隙分布存在着必然的联系。图4给出了常见4种金属堆积 类型与典型二元离子晶体结构型式之间的关系, 弄清楚这些结构之间的关联, 对掌握金属晶体和典 型二元离子晶体结构有很大的帮助, 而联系这些结构的纽带就是正四面体和正八面体空隙。

当正离子占据 $c c p$ 的全部正八面体空隙时, 得到 $\mathrm{NaCl}$ 型晶体结构; 反过来讲, 立方最密堆积的正 八面体空隙的位置亦即 $\mathrm{NaCl}$ 晶体中阳离子 $\mathrm{Na}^{+}$的位置(体心+棱心)。当正离子占据 $c c p$ 的全部正四面体 空隙时, 得到的晶体结构为反萤石型; 若将阳离子看成是 $c c p$, 阴离子占据全部正四面体空隙, 得到 的晶体结构为萤石型。同样可以得出 $c c p$ 的正四面体空隙的位置就是 $\mathrm{CaF}_{2}$ 晶体中 $\mathrm{F}^{-}$的位置 $(8$ 个小立方 体的中心)。进一步扩展, 如阴离子为立方简单堆积, 阳离子占据全部的立方体空隙, 得到的是 $\mathrm{CsCl}$ 型; 如果用相同的原子占据全部的立方体空隙, 得到的是A2型堆积; 如果阳离子占据一半的立方体 空隙, 得到的是 $\mathrm{CaF}_{2}$ 型。 


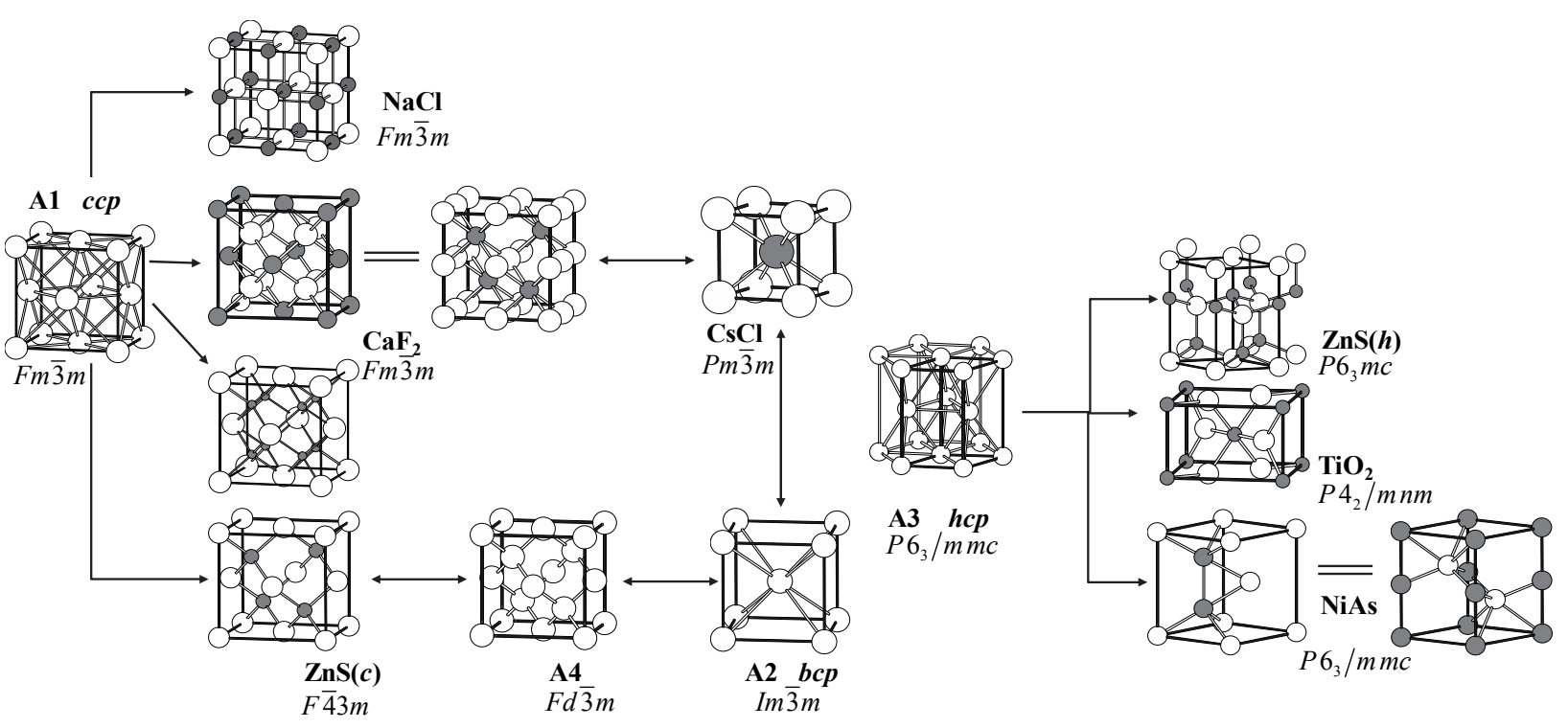

图4 堆积类型与典型离子晶体结构型式的关系

当正离子交错占据 $c c p$ 的一半正四面体空隙时, 得到的晶体结构为立方 $\mathrm{ZnS}$ 型, 如果是相同种类 原子占据了一半正四面体空隙, 也可考虑为将立方 $\mathrm{ZnS}$ 中的离子换成相同的原子, 得到的是金刚石 型堆积(A4)。如果将A4型堆积中所有空位(体心+棱心+交错4个小立方体中心)都填上相同原子, 得到 的是 $\mathrm{A} 2$ 型堆积; 也可以说将 $\mathrm{A} 1$ 堆积的所有正四面体空隙和正八面体空隙都填入同种原子, 得到的是 A2型堆积。

当正离子占据 $h c p$ 的全部正八面体空隙时, 得到的是 $\mathrm{NiAs}$ 型结构, $h c p$ 的正八面体空隙即为 $\mathrm{Ni}$ 原 子的位置(习惯以 $\mathrm{As}$ 为顶点划分晶胞); 如果与 $\mathrm{MgCl}_{2}$ 类似只占据其中一半八面体空隙(同层), 则其离 子晶体结构与 $\mathrm{CdI}_{2}$ 相同。当一半八面体空隙被占据时(非同层), 晶体结构变形后可得到金红石型, 因 此金红石型离子晶体中阴离子的堆积方式为伪六方。当 $h c p$ 一半正四面体空隙被占据时, 得到的是六 方 $\mathrm{ZnS}$ 结构, 因此可以从六方 $\mathrm{ZnS}$ 中 $\mathrm{Zn}^{2+}$ 的位置得知 $h c p$ 的正四面体空隙的位置。由于稳定性原因, 正 离子不能占据A3型堆积的全部正四面体空隙。

有了上述密堆积空隙和离子晶体在结构上的联系, 在学习掌握金属晶体和典型二元离子晶体的 结构中就可以对照堆积和简单离子晶体进行学习, 在南开大学的模型实习实践中, 这两部分模型实 习是合并在一起完成的(2次，4课时)。

\section{3 结语}

总之, 只要抓住空隙分布这个最重要的关键点, 在学习金属晶体和离子晶体结构时, 学生就可 以事半功倍, 更快地熟悉晶体结构, 理解和掌握晶体结构中的规律性。

\section{参 考 文 献}

[1] 朱月香. 大学化学, 2017, 32 (5), 61 .

[2] 孙宏伟. 结构化学. 北京: 高等教育出版社, 2016: 260-261.

[3] 丁萍, 田益民. 化学教育, 2013, No. 6, 84 . 